\title{
Effect of Supervisor-Subordinate Communication and Leadership Style on Organizational Commitment of Nurses in Health Care Setting
}

\author{
Shabnam Hamdi ${ }^{1} \&$ Mahmoud Rajablu ${ }^{2}$ \\ ${ }^{1}$ Department of Educational Studies, University Putra Malaysia, Serdang, Selangor, Malaysia \\ ${ }^{2}$ Department of Graduate School of Management, Multimedia University, Cyberjaya, Selangor, Malaysia \\ Correspondence: Shabnam Hamdi, Department of Educational Studies, Universiti Putra Malaysia, 43400, \\ Serdang, Selangor, Malaysia. Tel: 60-389-571-684. E-mail: Shabnam.hamdi@gmail.com
}

Received: August 13, 2012

Accepted: October 17, 2012

Online Published: November 2, 2012

doi:10.5539/ijbm.v7n23p7

URL: http://dx.doi.org/10.5539/ijbm.v7n23p7

\begin{abstract}
This study focuses on the role of supervisor-subordinate communication and leadership style on organisational commitment of nursing staff in the selected hospital. Meyer and Allen's instrument for multidimensional organizational commitment was utilized in this research. Leader Behavior Description Questionnaire was adapted from Stogdill's" (LBDQ-XII) form 12 and the items related to supervisor- subordinate communication were derived from two different researches by Heald, Girton and Kazanskya. The structured questionnaire was completed by 134 nursing staff of a major complex hospital in Tehran, Iran. In the demographic data, the majority of the respondent were 20 -30 years old female, had more than 10 years tenure and a Bachelor Degree. Overall, T-test analysis showed significant differences in type I and type II leader's consideration regarding level of affective and continuance commitment. Regression analysis indicated a significant contribution of communication exchange in affective commitment through type I and type II leader's consideration, whereas mutual communication showed a significant contribution in affective commitment only in type II consideration. There was no contribution of supervisor-subordinate communication in continuance commitment according to the two types of leader's consideration. In conclusion, the level of affective commitment is different among nursing staff and depends on quality of the leader and member communication and leaders' consideration. Especially in higher level of leader consideration and mutual communication, dependency of the nursing staff will increase. However, the continuance commitment depends on other factors which were not considered in current study.
\end{abstract}

Keywords: leader consideration, supervisor-subordinate communication, organisational commitment, nurse, hospital, Iran

\section{Introduction}

Organizational commitment is an important issue to achieve higher quality healthcare services and is linked to the job satisfaction amongst nursing staff (Alpander, 1990). Organizational Commitment is a major concept in organization research and in understanding of employee's behaviors at workplace. So, it would be useful for organization to consider human feelings and attitudes. There is a growing body of evidence to confirm the impact of organizational commitment as an outcome variable on an organization (Finegan, 2000; Gellatly, 1995; Hersey \& Blanchard, 1993). Therefore, a lack of commitment from the personnel can be harmful to the organization, resulting in poorer performance and higher costs (Caruana \& Calleya, 1998).

This study empirically investigates the relationship between leadership behavior, supervisor-subordinate communication and organisational commitment in Imam Khomeini Hospital (IKH). The IKH Complex is acclaimed as a competent hospital and occupies the highest Iranian rank in medical education, research and health affairs across the country. Currently, this medical complex is one of the leading providers of patient care in the capital. However, as stated in press (Mahdavi, 2009, January 25), the repetitions complains of patients on undesirable and weakness treatment and misbehaviors with them and their relatives by the nursing crew of IKH complex was announced as an essential challenge for the hospital management.

In order for healthcare organization to achieve its aims and objectives, the organization is required to employ skilled managers and employees to leverage interpersonal relations as the center of power. According to Khalili (2000) hospital management has not been recognized as a professional field in Iranian healthcare system. This has become the root of other issues and therefore strengthening hospital management as a comprehensive healthcare 
reform programme has been identified and planned by the Ministry of Health in Iran (Nayeri \& Negarandeh, 2009).

To investigate the problem further this paper reviews the existing literature on the relationships between leadership, supervisor-subordinate communication and nurses' commitment, and then generates and analyzes a series of testable hypotheses.

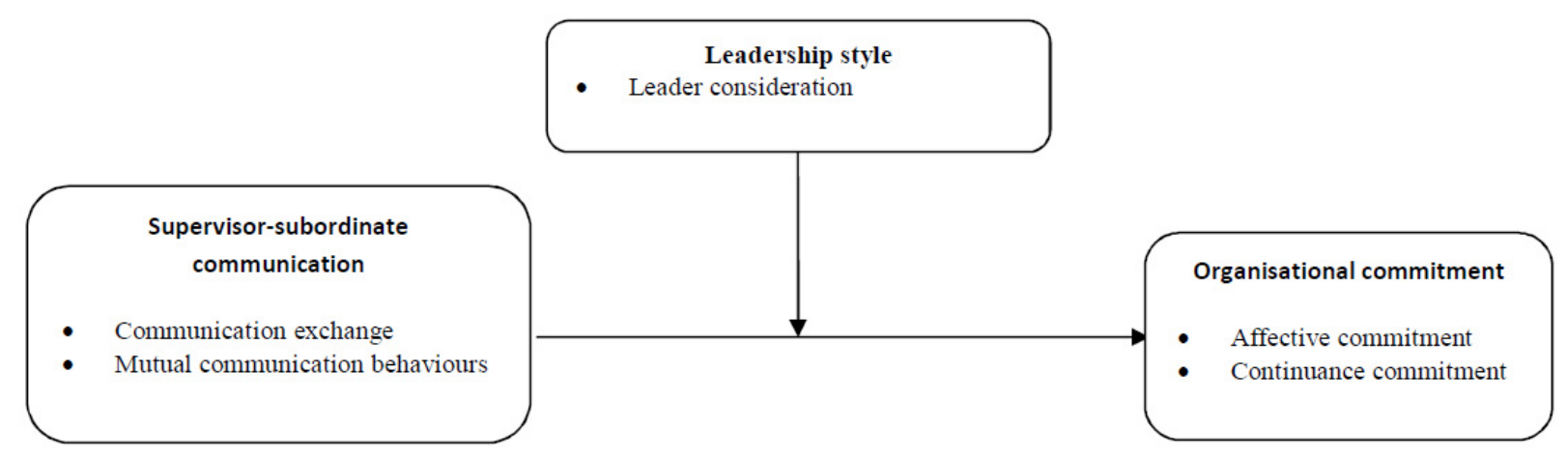

Figure 1. Conceptual framework of the study, moderating effect of leader consideration on relationship between supervisor-subordinate communication and organisational commitment

\section{Literature Review}

\subsection{Leadership and Organisational Commitment}

Leadership has been described as a motivational tool which can be used to influence others towards a specific outcome or objective. "No other role in organizations has received more interest than that of the leader" (Schwandt \& Marquardt, 2000b, p. 177). It is expected that leaders demonstration of supportive behavior towards their followers may influence the sense of duty of the follower's to remain committed to the organization (Anis, Kashif-ur-Rehman, Ijaz-Ur-Rehman, Khan, \& Humayoun, 2011).

In order to describe the feelings and thoughts of employees in an organization, a multidimensional construct was developed by Meyer and Allen (1984). It consists of affective commitment (based on positive feelings and attachment to the organization) and continuance commitment (based on costs associated with leaving the organization). Later, a multidimensional construct of organisational commitment was introduced a third component of commitment, while supporting the importance of affective commitment. It was named normative commitment that explains employees' decision to remain with the organization as something they ought to do.

Organizational commitment is an important construct in the discussion of behavioral elements which affect high performance and effectiveness. These components are also linked to the job satisfaction amongst nursing staff. Many studies have shown that employee commitment to the organization can aid higher productivity (Alpander, 1990; Mathieu \& Zajac, 1990; Riketta, 2002) as an important attitude for evaluating employees' intention to quit or remain with cumulative contribution to the organization (Riketta, 2002; Rynes, 2004). Employees with more affective commitment would be motivated to higher levels of performance and would make more meaningful contributions than employees who expressed continuance or normative commitment. They have indicated that staying with the organization was something they wanted to do, rather than something they needed or felt they ought to do (Liden, Wayne, \& Stilwell, 1993). Employees' commitment is also discussed in leadership streams.

The previous researches on leadership have found that the relationship between the two basic leadership variables (initiating structure and consideration) and organizational commitment varies across organizational contexts. It was noticed that there is a positive relationship between consideration by the leader to the commitment in hospitals, whereas structure initiation was positively related to the commitment among employees in city 
government departments. The evidence was also indicator of significant relation between displays of consideration by leaders and nurses' commitment (Eblen, 1987).

In fact, leader's behaviors and the relationships between leaders and members were believed to act as a motivational tool to influence members towards a desired outcome or objective (Isaac, Zerbe, \& Pitt, 2001). Employees feel that they are a part of the organization if they are supported by the organisational setting (Battistelli, Mariani, \& Bellò, 2006).

Indeed, when employees are treated with consideration, they display greater levels of commitment (DeCotiis \& Summers, 1987). Various studies have also indicated that effective supervisory communication and leadership behaviour (especially trust in supervisors) play an important role in increasing organisational commitment. Dyadic interpersonal trust predicts increased affective commitment and feelings of belonging to the organization (Lee, 2005; Mosser \& Walls, 2002; Perry, 2004). Nevertheless, employees' dissatisfaction at work causes them to quit or to lose their feelings of attachment to the organization (Shirbagi, 2007).

\subsection{Supervisor-Subordinate Communication and Leadership}

Communication and leadership share many of the same features (Hackman \& Johnson, 2004). Therefore, given the importance of the role of communication in leadership, it is not surprising that a great deal of attention has been paid to the search for a common communication style among effective leaders (Jablin, 1979). Interpersonal leader-subordinate communication is one of the major areas of organisational communication and proper communication and understanding must be clearly denoted between leaders and subordinates (Schwandt \& Marquardt, 2000a).

One of the more significant leadership research programs that developed after World War II was led by Edwin Fleishman and his associates at Ohio State University (OSU). This important research programme developed a two-factor theory of leadership; initiating structure and consideration. Consideration refers to the relationships within the group, and the tendency to establish good patterns and channels of communication and to initiate a structure for defining ways of getting the job done. A leader with a strong tendency towards initiating structures focuses on goals and results. Consideration is included in behaviors such as friendship, mutual trust, respect, warmth and communication between the leader and his/her followers (Fleishman, 1973; Stogdill, 1963). A leader with a high level of consideration supports open communication and participation (Hersey \& Blanchard, 1993; Ivancevich \& Matteson, 2002).

The model of supervisor-subordinate communication probably came from the traditional view of the supervisor-subordinate relationship as a dyad made up of two individuals. In traditional dyadic relationships, the supervisor could utilize different communication behaviour with different subordinates, depending on the nature of the relationship (Dansereau \& Markham, 1987; Hersey \& Blanchard, 1993). Supervisor-subordinate communication requires the best possible communication traits, behaviors, strategies and styles (Yrle, Hartman, \& Galle, 2002).

The result of a research at a non-federal hospital in the southeastern United States was indicated to increasing degree of commitment and satisfaction of the work life among nurses by increasing dyad communication between supervisor and subordinate. The survey utilized a group of communication items which dealt with employees' relationships with their supervisors. This factor was named communication exchange and defined as the perception of the degree to which the members of the dyad view each other as encouraging, answering questions and paying attention to suggestions. (Girton \& Heald, 2002).

Communication behavior was presented as a new dimension into communication studies by other scholars. This dimension talks about items as "asking questions" "giving suggestions" and "information exchanges with others." Mutual communication behaviour was found to have a positive relationship with job satisfaction and job retention at a hospital (Girton \& Heald, 2002; Heald, Girton, \& Kazanskya, 1999).

The researchers are always emphasizing on the vital role of communication in leadership to gain the desired outcome. They believe that leaders with high levels of consideration are more likely to be concerned about interpersonal relations and emphasizing communication with subordinates than leaders who follow initiating structural style (Jablin, 1979; Redding, 1972). In fact, communication between management and staff should be reciprocal and "two-way," and therefore building more "two-way" communication and involvement by the members will result in greater support from management (McCabe \& Garavan, 2008). 


\subsection{Supervisor-Subordinate Communication and Organisational Commitment}

Organizational commitment is one of the important factors for scholars in the discussion of communication behaviors in organizations. The strength of the leader-member relationship can predict organizationally significant outcomes including performance (Liden et al., 1993) and stronger organisational commitment (Liden, Wayne, \& Sparrowe, 2000; Schriesheim, Castro, \& Cogliser, 1999). The construct of leader-member exchange has the potential to identify some specific supervisors' behaviors that might improve subordinates' perception of the relationship (Johlke \& Duhan, 2001).

In addition, Australian researchers revealed that high-quality communication, such as clear, more accurate communication, better informed employees and more avenues for employees to communicate with management and co-workers, was positively related to job commitment (Johlke \& Duhan, 2001). Participation in decision-making, the adequacy of information and open communication were all positively related to organisational commitment (Putti, Aryee, \& Phua, 1990; Vuuren, de Jong, \& Seydel, 2007).

Indeed, low quality communication between leader and member is the reason to decrease the employee's attachment to the firm and promotion of willingness to leave the organization. Vice versa, the quality of communication between supervisor and subordinate and their feelings of attachment to the organization will be at the maximum level when the leaders are more considerate. Therefore, positive behaviors by leaders result in a stronger feeling of attachment of the employees and enhance their affective commitment. Hence, the following hypotheses are an initial step towards exploring the relationship between the dimensions of supervisor-subordinate communication and organisational commitment.

\section{Research Hypothesis}

From the above discussed literature the following hypotheses have been proposed in order to statistically analysis the research problem and achieve research objectives:

H 1. There is a significant difference between the low consideration (type I) and high consideration (type II) by the leader regarding level of affective commitment and high consideration has higher mean than low consideration.

H 2. There is a significant difference between the low consideration (type I) and high consideration (type II) by the leader regarding level of continuance commitment, and low consideration has lower mean than high consideration.

H 3. There is a significant difference in low consideration (type I) and high consideration (type II) by the leader regarding communication exchange.

H 4. There is a significant difference in low consideration (type I) and high consideration (type II) by the leader regarding mutual communication behaviour.

H 5. Communication exchange and mutual communication has a stronger association with affective and continuance commitment in high consideration (type II) than low consideration (type I).

H 6. Communication exchange and mutual communication has a stronger association with continuance commitment in high consideration (type II) than low consideration (type I).

\section{Subjects and Methods}

\subsection{Sample}

The unit of analysis is nursing staff. Therefore, the population of this research included all nursing staff working in the selected hospital at the time of the study. Permission was requested from Deputy Manager of Research at IKH Complex and an approval letter was released to start the research. Using simple random sampling, a total of 216 questionnaires were distributed among nurses who were working in the IKH and all of the respondents were assured of their anonymity. Overall 134 responses were received, which is a response rate of $62 \%$. A response rate of $60 \%$ to $70 \%$ is a good response rate and is adequate for analysis and reporting (Babbie, 2008). Table 1 shows the sample profile. 
Table 1. Sample profile $(\mathrm{n}=134)$

\begin{tabular}{lllllllllll}
\hline \multicolumn{3}{c}{ Sex } & \multicolumn{3}{c}{ Age (yr) } & \multicolumn{3}{c}{ Tenure $(\mathrm{yr})$} & \multicolumn{3}{c}{ Education } \\
\hline Male & Female & $\leq 30$ & $31-44$ & $>45$ & $\leq 2$ & $3-10$ & $10 \geq$ & ADN* & BS* & MS* $^{*}$ \\
18 & 116 & 59 & 63 & 12 & 35 & 35 & 64 & 10 & 123 & 1 \\
\hline
\end{tabular}

Note: ADN (Associate Degree in Nursing); BS (Bachelor of Sciences); MS (Master of Sciences).

\subsection{Instrument}

This study was conducted using the survey method and a set of questionnaires which had been translated into the local language (Persian). The reason is that the most of the nursing staff were not fluent in the English language. The questionnaire was used to measure the variables which were adopted from previous studies, and contained four main sections. Part A was structured to obtain information on the respondents' background. It consisted of four questions. Part B consisted of eight questions relating to leader consideration. These items were adapted from the Leader Behaviour Description Questionnaire (LBDQ-XII) Form 12 (Stogdill, 1963). This was developed during one of the Ohio State Leadership Project studies, and includes consideration (behavioral-orientation; the degree of communication, consultation, mutual trust, respect and warmth a leader toward followers) and structure initiation (task orientated relationship to achieve organizational goals) constructs of leader behaviour. The structure initiation construct of leader behavior was not employed here for the reason that this study aimed to examine relationships and behavioral orientation. Part $\mathrm{C}$ of the questionnaire comprised 11 questions relating to supervisor-subordinate communication as communication exchange (dyad relationship, encouraging, answering questions, paying attention) and mutual communication behaviors (information sharing from subordinate) which were used in the research. They were derived from studies in previous studies (Girton \& Heald, 2002; Heald et al., 1999). Part D consisted of 12 questions relating to organisational commitment (Meyer \& Allen, 1997). Organisational Commitment Questionnaire (OCQ) was adapted in this research. This instrument includes items that measure affective (feeling emotionally attached to the organization), continuance (beneficial reasons to stay in the organization) and normative commitment (ought to stay in the organization), but the normative commitment subscale was not included in this study as the aim was to test the effects of leadership on nurses' organisational commitment based on their desire and willingness to stay.

Each item was measured using 5-Likert scale with $1=$ strongly disagree and $5=$ strongly agree. In order to evaluate the extent of its reliability, the Cronbach's alpha coefficient was calculated. A pretest was carried out with 30 people in order to estimate the reliability of the questionnaire. For reasons of poor reliability, two items were removed after the pretest (Table 2).

Table 2 . The results of the reliability analysis after pretest

\begin{tabular}{ccccc}
\hline \multirow{2}{*}{ Reliability } & \multicolumn{2}{c}{ Leader consideration } & \multicolumn{2}{c}{ Continuance commitment } \\
\cline { 2 - 5 } & $\begin{array}{c}\text { Before item } \\
\text { deletion* }\end{array}$ & $\begin{array}{c}\text { After item } \\
\text { deletion }\end{array}$ & $\begin{array}{c}\text { Before item } \\
\text { deletion* }\end{array}$ & $\begin{array}{c}\text { After item } \\
\text { deletion }\end{array}$ \\
\hline Cronbach's alpha & 0.63 & 0.865 & 0.599 & 0.822 \\
\hline
\end{tabular}

*Note: leader consideration, item 10 \& continuance commitment, item 33 


\subsection{Analysis}

The perceptions of nurses about supervisor-subordinate communication and their leaders' behaviour were of interest to us. The zero-order correlations among all of the variables were computed in order to determine the degree to which the variables were related. These correlations are presented in Table 3 , along with the means and Cronbach's alphas for each variable. As shown in Table 3, the internal consistency obtained through Cronbach's alpha $(>0.7)$ in the current study is satisfactory (43). The zero-order correlations are generally consistent with our expectations.

Table 3. Means, correlations and reliabilities for all variables

\begin{tabular}{cccccccc}
\hline Variables & MEAN & SD & LC & CE & MC & CC & AC \\
\hline Leader consideration & 3.199 & 0.809 & $(0.865)$ & & & & \\
Communication exchange & 3.298 & 0.809 & 0.728 & $(0.936)$ & & & \\
Mutual communication & 3.429 & 0.987 & 0.739 & 0.841 & $(0.933)$ & & \\
Continuance commitment & 3.256 & 0.574 & 0.227 & 0.206 & 0.209 & $(0.822)$ & \\
Affective commitment & 3.185 & 0.894 & 0.485 & 0.410 & 0.411 & 0.362 & $(0.925)$ \\
\hline
\end{tabular}

Note: $(p<0.05)$ LC (leader consideration); CE (communication exchange); MC (mutual communication; CC (continuance commitment); AC (affective commitment). *Values on the diagonal are Cronbach's alphas.

Before testing the hypotheses, preliminary analysis were conducted to test for normality, linearity, multicolinearity and homoscedasticity for individual items. There was no concern of the assumptions. For most items, the skewness and kurtosis scores were stayed between the ranges of $+/-1.0$. According to Schumacker and Lomax (2004, p. 69), they were assumed to be normal.

The leader consideration was split at its median in order to be used as categorical variable (Cohen, 2003). An independent t-test analysis was used to test the differences between the two consideration types regarding the dimensions of (Hypotheses $1 \& 2$ ) and supervisor-subordinate communication organisational commitment (Hypotheses 3 \& 4). To test moderating effect of leadership on the relationship between supervisor-subordinate communication and organizational commitment simple regression analysis were performed individually for each types of leader's consideration.

\section{Results}

Table 4 reports the results of the differences between the two leader consideration groups. The results of the t-test (Table 4) showed significant differences $(p<0.005)$ between the two types of leader's consideration regarding affective and continuance commitment ( $\mathrm{H} 1 \& 2)$ and communication exchange, mutual communication (H $3 \& 4)$. In addition, the negative t-value means that $\mu 1<\mu 2$ and there is a highly significant difference between the two leader's consideration types regarding supervisor-subordinate communication and affective and continuance commitment. The mean scores alluded to a higher mean value in the high consideration group and a lower mean value in the low consideration group regarding organisational commitment and supervisor-subordinate communication. 
Table 4. Results of the independent samples t-test

\begin{tabular}{|c|c|c|c|c|c|c|}
\hline Variable & Leader consideration & $\mathrm{N}$ & Mean & Std. deviation & $t$ & $p$ \\
\hline \multirow{2}{*}{ Communication exchange } & Type I (low C) & & 2.581 & 0.99 & \multirow{2}{*}{-8.54} & \multirow{2}{*}{.000} \\
\hline & Type II (high C) & 79 & 3.797 & 0.68 & & \\
\hline \multirow{2}{*}{ Mutual communication behavior } & Type I (low C) & & 2.683 & 0.99 & \multirow{2}{*}{-7.86} & \multirow{2}{*}{.000} \\
\hline & Type II (high C) & 79 & 3.949 & 0.55 & & \\
\hline \multirow{2}{*}{ Affective commitment } & Type I (low C) & & 2.781 & 0.74 & \multirow{2}{*}{-4.69} & \multirow{2}{*}{.000} \\
\hline & Type II (high C) & 79 & 3.466 & 0.89 & & \\
\hline \multirow{2}{*}{ Continuance commitment } & Type I (low C) & 55 & 3.093 & 0.65 & \multirow{2}{*}{-2.83} & \multirow{2}{*}{0.005} \\
\hline & Type II (high C) & 79 & 3.369 & 0.49 & & \\
\hline
\end{tabular}

Note: ${ }^{*} \mathrm{p}<0.005, \mathrm{CI}(95 \%)$

Table 5 reports the results of regression analysis to identify moderating effect of two types of leader's consideration on relationship between communication exchange and affective commitment (H 5). Regression results for each types of leader's consideration show that communication exchange is significantly correlated with affective commitment in both types of leader's consideration, however it had higher association with affective commitment in type I (beta $=0.298, p<0.05 ; R^{2}=0.09$ ) than type II consideration (beta $=0.227, p<0.05 ; R^{2}=0.05$ ). As well, mutual communication is significantly correlated with affective commitment only in type II consideration (beta $\left.=0.343, p<0.05 ; R^{2}=0.004\right)$.

Table 5. Results of the linear regression analysis of the relationship between supervisor-subordinate communication and affective commitment across two types of leader's consideration

\begin{tabular}{|c|c|c|c|c|}
\hline \multirow{2}{*}{ Dependent Variables } & \multirow{2}{*}{$\begin{array}{l}\text { Leader consideration } \\
\text { (mediator) }\end{array}$} & \multicolumn{3}{|c|}{ Affective commitment (IV) } \\
\hline & & $\mathrm{N}$ & $\beta$ & $P$ \\
\hline \multirow{8}{*}{ Communication exchange } & Type I (low C) ${ }^{\mathrm{a}}$ & 55 & 0.298 & 0.027 \\
\hline & $\mathrm{R}^{2}=0.089$ & & & \\
\hline & $\mathrm{R}^{2}{ }_{\mathrm{adj}}=0.072$ & & & \\
\hline & $F(1,53)=5.181$ & & & \\
\hline & Type II (high C) ${ }^{\mathrm{b}}$ & 79 & 0.227 & 0.044 \\
\hline & $\mathrm{R}^{2}=0.052$ & & & \\
\hline & $\mathrm{R}^{2}{ }_{\mathrm{adj}}=0.039$ & & & \\
\hline & $\mathrm{F}(1,77)=4.189$ & & & \\
\hline \multirow{8}{*}{ Mutual communication } & Type I (low C) ${ }^{\mathrm{a}}$ & 55 & 0.177 & 0.196 \\
\hline & $\mathrm{R}^{2}=0.031$ & & & \\
\hline & $\mathrm{R}_{\text {adj }}^{2}=0.13$ & & & \\
\hline & $F(1,53)=1.719$ & & & \\
\hline & Type II (high C) ${ }^{b}$ & 79 & 0.343 & 0.002 \\
\hline & $\mathrm{R}^{2}=0.004$ & & & \\
\hline & $\mathrm{R}_{\mathrm{adj}}=0.106$ & & & \\
\hline & $F(1,77)=10.268$ & & & \\
\hline
\end{tabular}

Note: The values are standardized coefficient estimates for linear regression. All tests are two-tailed with ${ }^{*} p<0.05$ and $95 \%$ CI, ${ }^{a}$ low consideration, ${ }^{b}$ high consideration. 
Table 6 reports the results of regression analysis to identify moderating effect of the two types of leader's consideration on relationship between communication exchange and mutual communication behaviors with continuance commitment ( $\mathrm{H} 6)$. The result was the indicator of no significant correlation between the two factors of supervisor-subordinate communication with continuance commitment for any leader 'consideration types. This may reveal that continuance commitment is influenced by other factors than communication and leadership such as motivation of subordinates.

Table 6. Results of the linear regression analysis of the relationship between supervisor-subordinate communication and continuance commitment across two types of leader's consideration

\begin{tabular}{|c|c|c|c|c|}
\hline \multirow{2}{*}{ Dependent Variables } & \multirow{2}{*}{$\begin{array}{l}\text { Leader consideration } \\
\text { (mediator) }\end{array}$} & \multicolumn{3}{|c|}{ Continuance commitment (IV) } \\
\hline & & $\mathrm{N}$ & $\beta$ & $P$ \\
\hline \multirow{8}{*}{ Communication exchange } & Type I (low C) $)^{\mathrm{a}}$ & \multirow{4}{*}{55} & \multirow{4}{*}{0.098} & \multirow{4}{*}{0.478} \\
\hline & $\mathrm{R}^{2}=0.010$ & & & \\
\hline & $\mathrm{R}_{\text {adj }}^{2}=0.009$ & & & \\
\hline & $F(1,53)=0.510$ & & & \\
\hline & Type II (high C) ${ }^{\mathrm{b}}$ & \multirow{4}{*}{79} & \multirow{4}{*}{-0.023} & \multirow{4}{*}{0.842} \\
\hline & $\mathrm{R}^{2}=0.001$ & & & \\
\hline & $\mathrm{R}^{2}{ }_{\mathrm{adj}}=0.009$ & & & \\
\hline & $\mathrm{F}(1,77)=0.040$ & & & \\
\hline \multirow{8}{*}{ Mutual communication } & Type I (low C) ${ }^{\mathrm{a}}$ & \multirow{4}{*}{55} & \multirow{4}{*}{0.012} & \multirow{4}{*}{0.929} \\
\hline & $\mathrm{R}^{2}=0.000$ & & & \\
\hline & $\mathrm{R}^{2}{ }_{\mathrm{adj}}=0.019$ & & & \\
\hline & $\mathrm{F}(1,53)=0.008$ & & & \\
\hline & Type II (high C) ${ }^{\mathrm{b}}$ & \multirow{4}{*}{79} & \multirow{4}{*}{0.147} & \multirow{4}{*}{0.195} \\
\hline & $\mathrm{R}^{2}=0.022$ & & & \\
\hline & $\mathrm{R}^{2}{ }_{\mathrm{adj}}=0.009$ & & & \\
\hline & $F(1,77)=1.712$ & & & \\
\hline
\end{tabular}

Note: The values are standardized coefficient estimates for linear regression. All tests are two-tailed with ${ }^{*} p<0.05$ and $95 \% C I^{a}$ low consideration, ${ }^{b}$ high consideration.

\section{Discussion}

This study has explored the moderating effect of leader 'consideration in relationship between supervisor-subordinate communication and organisational commitment of nursing staff in an Iranian hospital. The major findings of this study can be summarized as follows:

1) The two types of leader's consideration produced significantly different results regarding organisational commitment (affective and continuance) and supervisor-subordinate communication (communication exchange and mutual communication behavior) and the mean value was higher in the type II (high consideration) than type I (low consideration). As many studies have pointed out, managers who are more attentive to nurses' perceptions are able to create the necessary conditions for higher productivity levels and can identify and promote higher commitment and productivity among clinical staff. In addition, negotiation between the leader and group or leader and members is beneficial in terms of bringing them closer, and such closeness will result in members to accept more duties and more feeling attached to the organization. Also with the assistance of the leader (Dehghan Nayeri, Nazari, Salsali, Ahmadi, \& Adib Hajbaghery, 2006) members will share their knowledge when they feel more attached to the organisational setting (Alashwal, Rahman, \& Beksin, 2011).

2) The significant relationships were found between communication exchange and affective commitment in both types of consideration, but this correlation is stronger through type I (low consideration) than type II (high consideration). These unexpected results alluded to unconditional working the subordinate with 
affective commitment. Likewise, the correlation between the mutual communication behaviors and affective commitment was stronger in type II (high consideration) than type I (low consideration). Similarly, the results of a survey by Iranian researchers in the Teaching Hospital of Hamedan University of Medical Sciences pointed to the creation of trusting supervisor-nurse communication when the hospital manager showed higher consideration towards the nursing staff (Delgoshaei, Tofighi, \& Kermani, 2009). So, high-quality leader and member communication and HR management throughout the healthcare context is considered to be an important aspect and an efficient way of improving the sense of dependency and attachment of nursing staff to the hospital. It is equally important to focus on right kinds of policies by HR management to build and enhance commitment of nursing staff (Hamdi \& Silong, 2011) and simultaneously improving healthcare services productivity (McNeese-Smith, 1997). As stated by Nyhan (1999), if supervisors consult employees when making decisions, the employees will perceive their participation as meaningful, and this increases affective commitment (Castrogiovanni \& Macy, 1990; DeCotiis \& Summers, 1987).

3) The relationship between continuance commitment and communication's dimensions through type I (low consideration) and type II (high consideration) was not significant. This may imply that the continuance commitment is influenced by many factors that were not considered in the study, such as the motivation of nursing staff. For leaders who are already perceived to be very considerate of their subordinates, the communication of relational messages could not satisfy any more of the subordinates' needs. In fact, the subordinate with this kind of commitment has not adequate flexibility in behaviors and personality to adaptability (Suliman \& Iles, 2000). They may be in need of better technical or administrative skills or benefits rather than consideration from their leaders. In this context, increasing the level of job security and creating positive environment were indicated as primary steps toward decreasing turnovers and cost of hiring new members (Bhuian \& Islam, 1996).

\section{Conclusion and Limitations}

This study was an effort to identify the importance of the role of communication (communication exchange \& mutual communication) and leadership style (leader consideration) in increasing commitment of nurses in health care setting. Cross-sectional and correlational nature of this study made it impossible to record the dynamic nature of the relationship between the leader and members of staff in the hospital in a systematic manner. For this reason, we cannot be sure whether a change in leadership causes a change in leader-subordinate communication or vice versa, and whether a change in communication causes a change in organisational commitment or vice versa. Furthermore, many situational factors were not investigated in this study, such as task orientation, structure initiation, the character of the tasks and subordinates and the organisational culture, which are believed to moderate the relationship between supervisor-subordinate communication and organisational commitment.

We suppose that the most insignificant effects in the study are consequent to small sample size (Rucker, Preacher, Tormala, \& Petty, 2011). Further studies should replicate this study in other Iranian organisational settings or professions in order to gain an in-depth understanding of organisational commitment in the context of organisational communication. In addition, qualitative methods can be helpful for obtaining more detailed information on nurses' perceptions of their work life in the healthcare setting. The results of this study derive from one source (the perceptions of nurses), and so there is a possibility of biases in this study. Therefore, a study of the perceptions, attitudes and visions of all of the members or beneficiaries of the healthcare system would result in a deeper understanding of the limitations and difficulties of the Iranian healthcare setting, leading to a more practical strategies and policies.

It is important to note that the relationships found in the current research should not be generalized to other studies without further systematic investigation.

\section{Acknowledgement}

The authors are gratefully acknowledged the whole crew of IKH that had helped and cooperated with us in this research. Also, we would like to thank Dr. Zulhamri Bin Abdullah for his guidance throughout this entire research. 


\section{References}

Alashwal, A. M., Rahman, H. A., \& Beksin, A. M. (2011). Knowledge sharing in a fragmented construction industry: On the hindsight. Scientific Research and Essays, 6(7), 1530-1536. http://dx.doi.org/10.5897/SRE10.645

Alpander, G. G. (1990). Relationship between commitment to hospital goals and job satisfaction: a case study of a nursing department. Health Care Management Review, 15(4), 51.

Anis, A., Kashif-ur-Rehman, Ijaz-Ur-Rehman, Khan, M. A., \& Humayoun, A. A. (2011). Impact of organizational commitment on job satisfaction and employee retention in pharmaceutical industry. African Journal of Business Management, 5(17), 7316-7324. http://dx.doi.org/10.5897/AJBM10.1296

Babbie, E. R. (2008). The practice of social research (12 ed.). Wadsworth Pub Co.

Battistelli, A., Mariani, M., \& Bellò, B. (2006). Normative commitment to the organization, support and self competence. In G. M. Minati, Pesa, E \& M. Abram (Eds.). Systemics of emergence: Research and development (pp. 515-526). USA: Springer.

Bhuian, S. N., \& Islam, M. S. (1996). Continuance commitment and extrinsic job satisfaction among a novel multicultural expatriate workforce. Midatlantic Journal of Business, 32, 35-46. http://ipac.kacst.edu.sa/eDoc/eBook/2376.pdf

Caruana, A., \& Calleya, P. (1998). The effect of internal marketing on organisational commitment among retail bank managers. International Journal of Bank Marketing, 16(3), 108-116. http://dx.doi.org/10.1108/02652329810213510

Castrogiovanni, G. J., \& Macy, B. A. (1990). Organizational information-processing capabilities and degree of employee participation. Group \& Organization Management, 15(3), 313-336. http://dx.doi.org/10.1177/105960119001500306

Cohen, J. (2003). Applied multiple regression/correlation analysis for the behavioral sciences (Vol. 1): Lawrence Erlbaum.

Dansereau, F., \& Markham, S. E. (1987). Superior-subordinate communication: Multiple levels of analysis. In Jablin, Fredric M. (Ed); Putnam, Linda L. (Ed); Roberts, Karlene H. (Ed); Porter, Lyman W. (Ed), (1987). Handbook of organizational communication: An interdisciplinary perspective, (pp. 343-388). Thousand Oaks, CA, US: Sage Publications, Inc, 781 pp.

DeCotiis, T. A., \& Summers, T. P. (1987). A path analysis of a model of the antecedents and consequences of $\begin{array}{llll}\text { organizational } \quad \text { Human } & \text { relations, } & 40(7), & \text { 445-470. }\end{array}$ http://dx.doi.org/10.1177/001872678704000704

Dehghan Nayeri, N., Nazari, A. A., Salsali, M., Ahmadi, F., \& Adib Hajbaghery, M. (2006). Iranian staff nurses' views of their productivity and management factors improving and impeding it: a qualitative study. Nursing \& Health Sciences, 8(1), 51-56. http://dx.doi.org/10.1186/1478-4491-3-9

Delgoshaei, B., Tofighi, S., \& Kermani, B. (2009). The relationship between organizational climate and organizational commitment in teaching hospitals of Hamedan University of medical sciences. Ofogh-e-Danesh Journal, 14(4), 60-68.

Eblen, A. L. (1987). Communication, leadership, and organizational commitment. Communication Studies, 38(3-4), 181-195. http://dx.doi.org/10.1080/10510978709368241

Finegan, J. E. (2000). The impact of person and organizational values on organizational commitment. Journal of occupational and Organizational Psychology, 73(2), 149-169. http://dx.doi.org/10.1348/096317900166958

Fleishman, E. A. (1973). Twenty years of consideration and structure. Current developments in the study of leadership, 1, 37.

Gellatly, I. R. (1995). Individual and group determinants of employee absenteeism: Test of a causal model. Journal of Organizational Behavior, 16(5), 469-485. http://dx.doi.org/10.1002/job.4030160507

Girton, M. K., \& Heald, G. R. (2002). A new model of leader-member exchange: Adding a communication exchange dimension. Paper presented at the A paper presented at the meeting of the Applied Communication Division of the National Communication Association, New Orleans, LA.

Hackman, M. Z., \& Johnson, C. E. (2004). Leadership: A communication perspective: Waveland Press Long Grove, IL. 
Hamdi, S., \& Silong, A. D. (2011). The influence of career stage and employment status on organisational commitment amongst nurses. Paper presented at the Aceh Development International Conference, UKM-Bangi, Malaysia.

Heald, G. R., Girton, M. K., \& Kazanskya, N. V. (1999). The impact of management-employee relations and communication exchanges on nurses' job satisfaction, and nurses' near-term versus long-term job retention plans. Paper presented at the Paper presented at the National Communication Association's Annual Conference, Chicago, IL.

Hersey, P., \& Blanchard, K. H. (1993). Management of organizational behavior: Utilizing human resources: Prentice-Hall, Inc.

Isaac, R. G., Zerbe, W. J., \& Pitt, D. C. (2001). Leadership and motivation: The effective application of expectancy theory. Journal of Managerial Issues, 212-226.

Ivancevich, J. M., \& Matteson, M. T. (2002). Organisation behaviour and management, London: McGraw-Hill.

Jablin, F. M. (1979). Superior-subordinate communication: The state of the art. Psychological bulletin, 86(6), 1201-1222. http://dx.doi.org/10.1037/0033-2909.86.6.1201

Johlke, M. C., \& Duhan, D. F. (2001). Supervisor communication practices and boundary spanner role ambiguity. Journal of Managerial Issues, 13(1), 87-101. Retrieved from http://www.jstor.org/stable/40604335

Khalili, E. (2000). Hospital administration in Iran and different countries. Paper presented at the Hospital Paper presented at the the Hospital Administration Conference, Tehran, Iran.

Lee, J. (2005). Effects of leadership and leader-member exchange on commitment. Leadership \& Organization Development Journal, 26(8), 655-672. http://dx.doi.org/10.1108/01437730510633728

Liden, R. C., Wayne, S. J., \& Sparrowe, R. T. (2000). An examination of the mediating role of psychological empowerment on the relations between the job, interpersonal relationships, and work outcomes. Journal of applied psychology, 85(3), 407-416. http://dx.doi.org/10.1037/0021-9010.85.3.407

Liden, R. C., Wayne, S. J., \& Stilwell, D. (1993). A longitudinal study on the early development of leader-member exchanges. Journal of applied psychology, 78(4), 662.

Mahdavi, B. (2009). Requirement of massive investment in the governmental hospitals; Services qualification in governmental hospitals at a glance $1 \& 2$. The Ettelaat, 6.

Mathieu, J. E., \& Zajac, D. M. (1990). A review and meta-analysis of the antecedents, correlates, and consequences of organizational commitment. Psychological bulletin, 108(2), 171. http://dx.doi.org/10.1037/0033-2909.108.2.171

McCabe, T. J., \& Garavan, T. N. (2008). A study of the drivers of commitment amongst nurses: The salience of training, development and career issues. Journal of European Industrial Training, 32(7), 528-568. http://dx.doi.org/10.1108/03090590810899829

McNeese-Smith, D. K. (1997). The influence of manager behavior on nurses' job satisfaction, productivity, and commitment. Journal of Nursing Administration, 27(9), 47.

Meyer, J. P., \& Allen, N. J. (1984). Testing the side-bet theory of organizational commitment: Some methodological considerations. Journal of applied psychology, 69(3), 372. http://dx.doi.org/10.1037/0021-9010.69.3.372

Meyer, J. P., \& Allen, N. J. (1997). Commitment in the workplace: Theory, research, and application.Sage publications, inc.

Mosser, N. R., \& Walls, R. T. (2002). Leadership frames of nursing chairpersons and the organizational climate in baccalaureate nursing programs. Southern Online Journal of Nursing Research, 3(2), 11.

Nayeri, N. D., \& Negarandeh, R. (2009). Conflict among Iranian hospital nurses: a qualitative study. Human Resources for Health, 7.

Nyhan, R. C. (1999). Increasing affective organizational commitment in public organizations. Review of Public Personnel Administration, 19(3), 58-70. http://dx.doi.org/10.1177/0734371X9901900305

Perry, R. W. (2004). The relationship of affective organizational commitment with supervisory trust. Review of Public Personnel Administration, 24(2), 133-149. http://dx.doi.org/10.1177/0734371X03262452

Putti, J. M., Aryee, S., \& Phua, J. (1990). Communication relationship satisfaction and organizational 
commitment. Group \& Organization Management, $15(1), \quad 44-52$. http://dx.doi.org/10.1177/105960119001500104

Redding, W. C. (1972). Communication within the organization: An interpretive review of theory and research: Industrial Communication Council New York.

Riketta, M. (2002). Attitudinal organizational commitment and job performance: a meta-analysis. Journal of Organizational Behavior, 23(3), 257-266. http://dx.doi.org/10.1002/job.141

Rucker, D. D., Preacher, K. J., Tormala, Z. L., \& Petty, R. E. (2011). Mediation analysis in social psychology: Current practices and new recommendations. Social and Personality Psychology Compass, 5(6), 359-371. http://dx.doi.org/10.1111/j.1751-9004.2011.00355.x

Rynes, S. L. (2004). Where do we go from here? Imagining new roles for human resources. Journal of Management Inquiry, 13(3), 203-213. http://dx.doi.org/10.1177/1056492604268202

Schriesheim, C. A., Castro, S. L., \& Cogliser, C. C. (1999). Leader-member exchange (LMX) research: A comprehensive review of theory, measurement, and data-analytic practices. The Leadership Quarterly, 10(1), 63-113.

Schumacker, R. E., \& Lomax, R. G. (2004). A beginner's guide to structural equation modeling (Vol. 1): Lawrence Erlbaum.

Schwandt, D. R., \& Marquardt, M. J. (2000a). Organizational learning: From world-class theories to global best practices: CRC.

Schwandt, D. R., \& Marquardt, M. J. (2000b). Organizational learning: From world-class theories to global best practices: CRC.

Shirbagi, N. (2007). Exploring organizational commitment and leadership frames within Indian and Iranian higher education institutions. Bulletin of Education \& Research, 29(1), 17-32.

Stogdill, R. M. (1963). Manual for the leader behavior description questionnaire-Form XII. Columbus: Ohio State University, Bureau of Business Research.

Suliman, A., \& Iles, P. (2000). Is continuance commitment beneficial to organizations? Commitment-performance relationship: A new look. Journal of Managerial Psychology, 15(5), 407-422. http://dx.doi.org/10.1108/02683940010337158

Vuuren, M. V., De Jong, M. D. T., \& Seydel, E. R. (2007). Direct and indirect effects of supervisor communication on organizational commitment. Corporate Communications: An International Journal, 12(2), 116-128. http://dx.doi.org/10.1108/13563280710744801

Yrle, A. C., Hartman, S., \& Galle, W. P. (2002). An investigation of relationships between communication style and leader-member exchange. Journal of Communication Management, 6(3), 257-268. http://dx.doi.org/10.1108/13632540210807099 